\title{
Diradical reaction mechanisms in [3 + 2]-cycloadditions of hetaryl thioketones with alkyl- or trimethylsilyl-substituted diazomethanes
}

\author{
Grzegorz Mlostoń ${ }^{* 1}$, Paulina Pipiak ${ }^{1}$ and Heinz Heimgartner ${ }^{2}$
}

\author{
Full Research Paper \\ Address: \\ ${ }^{1}$ Department of Organic and Applied Chemistry, University of Łódź, \\ Tamka 12, PL 91-403 Łódź, Poland and 2Department of Chemistry, \\ University of Zürich, Winterthurerstrasse 190, CH-8057 Zürich, \\ Switzerland \\ Email: \\ Grzegorz Mlostoń* - gmloston@uni.lodz.pl \\ * Corresponding author \\ Keywords: \\ [3 + 2]-cycloadditions; diazoalkanes; diradicals; 1,3-dithiolanes; \\ reaction mechanisms; thioketones
}

Beilstein J. Org. Chem. 2016, 12, 716-724.

doi:10.3762/bjoc. 12.71

Received: 15 January 2016

Accepted: 23 March 2016

Published: 14 April 2016

Associate Editor: C. Stephenson

(c) 2016 Mlostoń et al; licensee Beilstein-Institut.

License and terms: see end of document.

\begin{abstract}
Reactions of dihetaryl and aryl/hetaryl thioketones with 2-diazopropane, diazoethane, and (trimethylsilyl)diazomethane were studied at variable temperature. The experiments showed that reactions with 2-diazopropane carried out at $-75^{\circ} \mathrm{C}$ occur mainly via the initially formed, relatively stable 1,3,4-thiadiazolines as products of the [3+2]-cycloaddition of the diazo dipole onto the $\mathrm{C}=\mathrm{S}$ bond. The latter decompose only at higher temperature $\left(\mathrm{ca} .-40{ }^{\circ} \mathrm{C}\right)$ to generate thiocarbonyl $S$-isopropanide. In the absence of the starting thioketone, the corresponding thiiranes and/or ethene derivatives, formed from them via spontaneous desulfurization, are the main products. In contrast, reactions with diazoethane occurred predominantly via initially formed diradicals, which in cascade processes gave sterically crowded 4,4,5,5-tetrahetaryl-1,3-dithiolanes as major products. Finally, the reaction of dihetaryl thioketones with (trimethylsilyl)diazomethane occur smoothly at $-75^{\circ} \mathrm{C}$ leading to the corresponding $4,4,5,5$-tetrahetaryl-1,3-dithiolanes as the exclusive [3+2]-cycloadducts formed via a cascade of postulated diradicals. The presence of S or Se atoms in the hetaryl rings is of importance for stabilizing diradical intermediates. Remarkably, in no single case, the 'head-to-head dimerization' of aryl/ hetaryl and dihetaryl substituted thiocarbonyl ylides was observed.
\end{abstract}

\section{Introduction}

Cycloaddition reactions belong to the most important classes of organic reactions, and [3+2]- cycloadditions, also known as 1,3-dipolar cycloadditions or Huisgen reactions, offer a universal tool for the preparation of five-membered heterocycles with a variable number of heteroatoms in the ring [1,2].
In addition to their practical importance, discussions on the mechanism contribute significantly to the development of fundamental concepts in organic chemistry [3-7]. The first general concept of concerted [3+2]-cycloadditions was formulated by Huisgen [4]. However, some time later, Huisgen and 
co-workers reported stepwise [3+2]-cycloadditions via zwitterionic intermediates $[8,9]$. Large differences of energies of the frontier orbitals of dipole and dipolarophile, as well as sterically demanding groups at the terminus of the dipole, were pointed out as requirements for the initiation of the 'zwitterionic pathway'. In addition to the experimental findings, new reports dealing with computational studies aimed at the demonstration of new zwitterionic [3+2]-cycloadditions were published [10-12]. Finally, a third concept for the interpretation of the mechanism of [3+2]-cycloadditions, formulated by Firestone, is based on the assumption that they occur via diradical intermediates [13-15].

Reactions of aromatic thioketones with diazomethane are well established. For example, in the case of thiobenzophenone (1a), the reaction performed at $-65^{\circ} \mathrm{C}$ occurs without evolution of $\mathrm{N}_{2}$ and the in situ formed 2,2-diphenyl-1,3,4-thiadiazoline 2a can be subsequently used as a precursor of the reactive thiobenzo- phenone $S$-methanide (a thiocarbonyl ylide) 3a at ca. $-45^{\circ} \mathrm{C}$, when the evolution of $\mathrm{N}_{2}$ takes place [16-20]. An analogous course of the reaction with diazomethane was observed in the case of thiofluorenone (1b, Scheme 1).

When the decomposition of $\mathbf{2} \mathbf{a}$ or $\mathbf{2} \mathbf{b}$ was performed in the presence of a suitable dipolarophile, the corresponding [ $3+$ 2]-cycloadducts were formed, whereas in the absence of a dipolarophile, the 'head-to-head dimerization' leading to 2,2,3,3tetraaryl-1,4-dithianes $\mathbf{4 a , b}$ is the exclusive reaction.

Heteroatoms such as $\mathrm{S}$ and Se are known to stabilize radical centers [21]. In our ongoing studies on thioketones and their applications in the cycloaddition chemistry, we described in a recent publication the unexpected course of the reaction of diazomethane with aryl/selenophen-2-yl thioketones of type 1c, leading to unusual dimers 5 of intermediate thiocarbonyl ylides of type 3c [22] (Scheme 2). In a competitive reaction, the latter

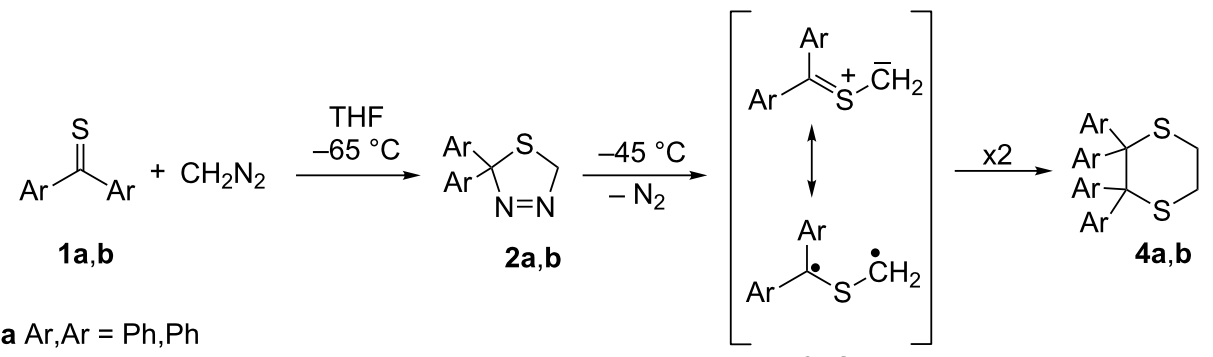

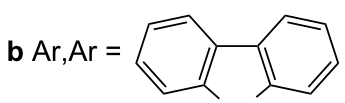

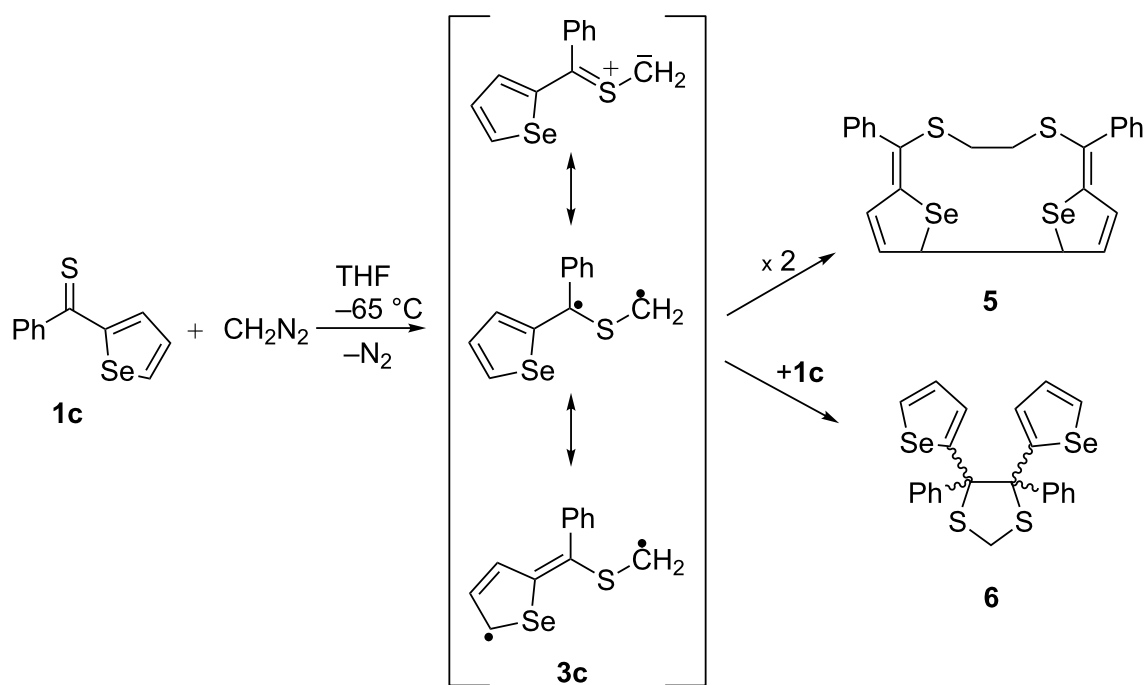


react with the starting thioketone $1 \mathbf{c}$ to give 1,3-dithiolanes of type 6 which are, apparently, also formed via a diradical pathway, leading to the sterically crowded 4,4,5,5-tetrasubstituted isomers exclusively.

In other studies, performed with cycloaliphatic thioketones, e.g. with adamantane-2-thione or 2,2,4,4-tetramethyl-3-thioxocyclobutanone, the growing stability of the corresponding 1,3,4-thiadiazolines obtained in reactions with diazomethane, diazoethane, and 2-diazopropane was reported based on kinetic data [9,17-19]. The same tendency was observed in a series of reactions with aromatic thioketones: for example, the reaction of thiobenzophenone (1a) with diazoethane performed at $-70{ }^{\circ} \mathrm{C}$ led to the formation of a relatively stable 2 -methyl-1,3,4-thiadiazoline, which could be identified in the low temperature ${ }^{1} \mathrm{H}$ NMR spectrum [20]. To the best of our knowledge, there are no reports on the course of reactions of either diaryl, aryl/ hetaryl or dihetaryl thioketones with 2-diazopropane.

Prompted by these observations, we decided to examine reactions of aryl/hetaryl and dihetaryl thioketones 1 with some diazomethane derivatives, such as 2-diazopropane (7a), diazoethane (7b), and (trimethylsilyl)diazomethane (7c), and to compare their outcome with earlier reported reactions with diazomethane [22]. An important question was if in these reactions the corresponding 2-substituted 1,3,4-thiadiazolines of type 2 can be obtained at low temperature and subsequently used as precursors of new thiocarbonyl ylides. The latter may be potentially useful for the $[3+2]$-cycloaddition reactions with diverse dipolarophiles leading to five-membered $S$-heterocycles, such as di- and tetrahydrothiophenes, 1,3-oxathiolanes, 1,3dithiolanes, etc.

\section{Results and Discussion}

The first experiment performed with thiobenzophenone (1a) and 2-diazopropane (7a) at ca. $-75^{\circ} \mathrm{C}$ in THF led to a change of the blue color of the solution without evolution of $\mathrm{N}_{2}$. The addition of the solution of 7a was continued until the color of the mixture changed to pale red. The mixture was warmed up, and around $0{ }^{\circ} \mathrm{C}$ the evolution of $\mathrm{N}_{2}$ was observed. The ${ }^{1} \mathrm{H}$ NMR analysis of the crude product revealed the presence of only one singlet for two Me groups located at $1.62 \mathrm{ppm}$. After chromatographic work-up, the only product isolated as colorless crystals was identified as 2,2-dimethyl-3,3-diphenylthiirane (8a; Scheme 3, Table 1). The same result was obtained when the reaction was carried out at ca. -60 or $-15{ }^{\circ} \mathrm{C}$.

Similar experiments were performed with thiofluorenone (1b) and 7a. Whereas at $-75{ }^{\circ} \mathrm{C}$ and $-60{ }^{\circ} \mathrm{C}$ the corresponding thiirane $\mathbf{8 b}$ and ethene $\mathbf{9 b}$, formed via spontaneous desulfurization of $\mathbf{8 b}$, were obtained as the sole products, in the experiment carried out at $-15{ }^{\circ} \mathrm{C}$, the sterically crowded 1,3-dithiolane $10 \mathrm{~b}$ was also detected as a minor product (14\% yield, Table 1). In the latter case, thiirane $\mathbf{8 b}$ and ethene $\mathbf{9 b}$ were found in 24 and 37\% yield, respectively. According to the literature, reaction of thiobenzophenone (1a) with diazoethane (7b) performed at $-75{ }^{\circ} \mathrm{C}$ led to 5-methyl-2,2-diphenyl-1,3,4-thiadiazoline as the exclusive product [20]. After warming the reaction mixture to room temperature, the only products observed in the mixture were 2,2-diphenyl-3-methylthiirane (8i) and 1,1diphenylpropene (9i) as the product of its desulfurization. On the other hand, the experiment with $1 \mathbf{a}$ and $7 \mathbf{b}$ performed at room temperature led to the 1,3-dithiolane $\mathbf{1 0} \mathbf{i}$ as the major product (87\%) accompanied by small amounts of thiirane $8 \mathbf{i}$ and ethene $9 \mathrm{i}[23]$.

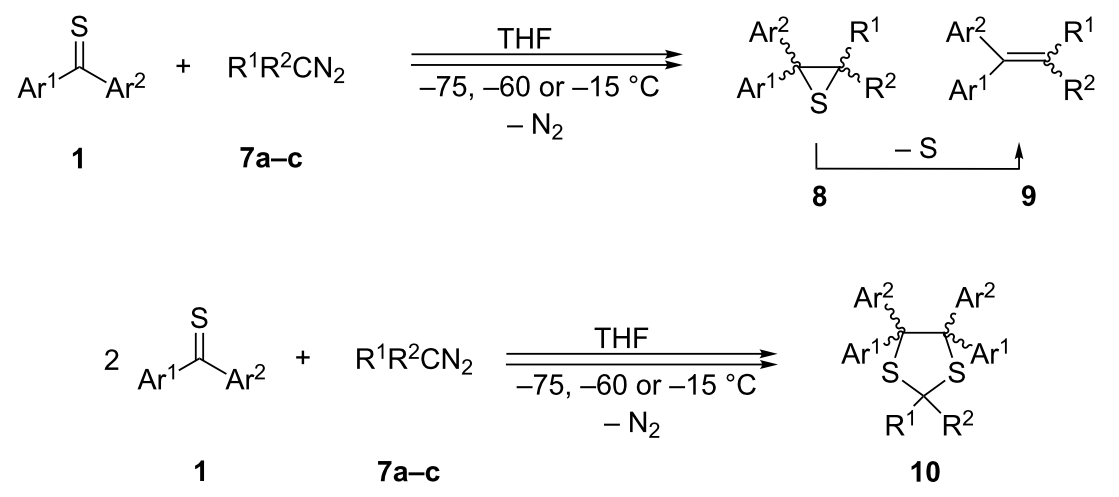

a: $R^{1}, R^{2}=M e ; b: R^{1}=M e, R^{2}=H ; c: R^{1}=M e_{3} S i, R^{2}=H$ 
A different result was observed in the reaction of $7 \mathbf{a}$ with di(thiophen-2-yl) thioketone (1d). In that case, the reaction at $-75{ }^{\circ} \mathrm{C}$ afforded also the expected thiirane $8 \mathbf{d}$ as the major product, accompanied by small amounts of the corresponding alkene 9d. However, in that case 4,4,5,5-tetrasubstituted 1,3- dithiolane 10d was also observed (7\%). The amount of the latter product increased to $36 \%$ when the reaction was performed at $-60{ }^{\circ} \mathrm{C}$ and to $58 \%$ at $-15{ }^{\circ} \mathrm{C}$. The corresponding experiments with $\mathbf{1 c}$ and $\mathbf{7 b}$ led to increased amounts of 1,3-dithiolane $\mathbf{1 0 k}$, established as $43 \%$ at $-75{ }^{\circ} \mathrm{C}, 81 \%$ at $-60{ }^{\circ} \mathrm{C}$, and $85 \%$ at

Table 1: Reactions of aryl/aryl, aryl/hetaryl, and hetaryl/hetaryl thioketones 1 with 2-diazopropane (7a), diazoethane (7b), and (trimethylsilyl)diazomethane (7c).

\begin{tabular}{|c|c|c|c|c|c|c|}
\hline Entry & Thioketone 1 & Diazoalkane 7 & $T\left[{ }^{\circ} \mathrm{C}\right]$ & Product $\mathbf{8 / 9}$ & Yields 8/9 [\%] ${ }^{a}$ & $\begin{array}{cc}\text { Product } 10 & \text { Yield } 10 \text { (or 4) } \\
\text { (and/or 4) } & {[\%]^{a}}\end{array}$ \\
\hline
\end{tabular}<smiles>S=C(c1ccccc1)c1ccccc1</smiles>

$1 \mathrm{a}$<smiles>S=C1c2ccccc2-c2ccccc21</smiles>

$1 \mathrm{~b}$

3<smiles>S=C(c1ccccc1)c1ccc[se]1</smiles>

1c

4<smiles>S=C(c1cccs1)c1cccs1</smiles>

$1 d$

5<smiles>S=C(c1ccc[se]1)c1ccc[se]1</smiles>

$1 \mathrm{e}$

6<smiles>S=C(c1ccccc1)c1cccs1</smiles>

$1 f$

7<smiles>S=C(c1ccccc1)c1ccco1</smiles><smiles>S=C(c1ccc(Cl)cc1)c1ccc[se]1</smiles>

$1 \mathrm{~h}$ $\stackrel{7 b}{7 b} \quad c r t$

$8 i / 9 i$

$$
\begin{aligned}
& \mathrm{R}^{1}=\mathrm{R}^{2}=\mathrm{Me} \quad \begin{array}{l}
-15 \\
-60 \\
-75
\end{array} \\
& \begin{array}{c}
86 \\
80\left(76^{b}\right) \\
75
\end{array}
\end{aligned}
$$

$61\left(41^{\mathrm{b}}\right)$

$8 b / 9 b$

85

$10 \mathrm{~b}$

$14\left(12^{\mathrm{d}}\right)$

76

$8 c / 9 c$

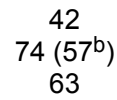

$10 \mathrm{c}$

61

7a $\quad-60$

63

$3\left(11^{\mathrm{d}, \mathrm{e}}\right)$

18

$7 a$

$-15$

-60
-75

$8 d / 9 d$

56
$87\left(75^{\mathrm{b}}+2^{\mathrm{c}}\right)$
97

$10 d$

58

$36\left(32^{d}\right)$

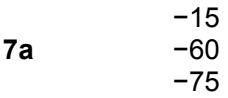

$8 e / 9 e$

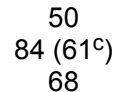

$10 \mathrm{e}$

49
$20\left(17^{d}\right)$
27

$7 a$

$-15$

$8 f / 9 f$

$40\left(17^{b}+7^{c}\right)$

$10 f$

$67\left(63^{\mathrm{d}, \mathrm{e}}\right)$

85
96

38

$7 a$

$-15$

-60
-75

$8 g / 9 g$

$51 \stackrel{38}{\left(40^{c}\right)}$

$\log \quad 31\left(28^{\mathrm{d}, \mathrm{e}}\right)$

$\begin{array}{cccc} & -15 & & 36 \\ 7 a & -60 & \mathbf{8 h} / 9 \mathbf{h} & 88\left(65^{\mathrm{C}}\right) \\ & -75 & & 72\end{array}$

10h

68
$21\left(17^{\mathrm{d}, \mathrm{e}}\right)$
21

87

traces (see, ref. [23]) $93^{b}+3^{c}$

(see, ref. [20]) 
Table 1: Reactions of aryl/aryl, aryl/hetaryl, and hetaryl/hetaryl thioketones 1 with 2-diazopropane (7a), diazoethane (7b), and (trimethylsilyl)diazomethane (7c). (continued)

10<smiles>S=C1c2ccccc2-c2ccccc21</smiles>

$1 b$

11<smiles>S=C(c1cccs1)c1cccs1</smiles>

1d

12<smiles>S=C(c1ccc[se]1)c1ccc[se]1</smiles>

$1 e$

13<smiles>S=C(c1ccccc1)c1cccs1</smiles>

$1 f$

14<smiles>S=C(c1ccccc1)c1ccc[se]1</smiles>

1c<smiles>S=C(c1ccccc1)c1ccccc1</smiles>

$1 a$<smiles>S=C1c2ccccc2-c2ccccc21</smiles>

$1 b$<smiles>S=C(c1cccs1)c1cccs1</smiles>

1d<smiles>S=C(c1ccc[se]1)c1ccc[se]1</smiles>

$1 e$ $\begin{array}{cccccc} & -15 & 3 & & 82 \\ \mathbf{7 b} & -60 & \mathbf{8 j} / 9 \mathbf{j} & 9\left(6^{\mathrm{c}}\right) & \mathbf{1 0 j} & 73\left(61^{\mathrm{d}}\right) \\ & -75 & & 14 & & 57\end{array}$

$-15$

-60
-75

8k/9k

39
$32\left(25^{\mathrm{c}}\right)$
69

10k

85

$81\left(72^{\mathrm{d}}\right)$

43

$-15$

-60
-75

$81 / 91$

11

$5\left(3^{c}\right)$

101

76

$86\left(79^{d}\right)$

87

$-15$

$7 b$

-15
-60
-75

$8 m / 9 m$

6
$59\left(48^{c}\right)$

$10 \mathrm{~m}$

79

62

$35\left(27^{\text {d,e }}\right)$

28

$7 b$

-15
-60

-60
-75

$8 n / 9 n$

20
$83\left(71^{c}\right)$
65

75

$36\left(28^{\mathrm{d}, \mathrm{e}}\right)$

30

10o $\quad 36\left(33^{\mathrm{d}}\right)$

and $4 \mathrm{c} \quad 39\left(22^{f}\right)$

$\mathrm{R}^{1}=\mathrm{Me}_{3} \stackrel{\text { Sc }}{\mathrm{Si}}, \mathrm{R}^{2}=\mathrm{H} \quad-75$

$-$

4d

$53^{f}$ see ref. [26]

7c

$-75$

$-$

$10 r$

$95\left(87^{d}\right)$

7c

$-75$

aYields determined by ${ }^{1} \mathrm{H}$ NMR with a weighed amount of 1,1,2,2-tetrachloroethane as a standard. ${ }^{b}$ Yield of isolated product 8 . ${ }^{\mathrm{c}}$ Yield of isolated product 9. ${ }^{d}$ Yield of isolated product 10. ${ }^{e}$ Isolated as mixtures of isomeric products. ${ }^{\text {fYield of isolated product } 4 .}$

$-15{ }^{\circ} \mathrm{C}$ (Table 1). The same tendency, i.e., an increasing amount of 1,3-dithiolanes $\mathbf{1 0}$ in the case of the less-substituted diazoethane (7b) and at higher temperature, was observed for the reactions with thiofluorenone (1b), di(selenophen-2-yl)-, (phenyl)(thiophen-2-yl)-, (phenyl)(selenophen-2-yl)-, and other aryl hetaryl thioketones 1 (Table 1). As mentioned before, in some cases tri- and tetrasubstituted thiiranes partially underwent spontaneous extrusion of sulfur to form the corresponding tri- or tetrasubstituted ethene derivatives 9. In these cases, complete desulfurization was achieved by treatment of the reaction mixture with tris(diethylamino)phosphine, and the respective ethenes 9 were isolated as the final products. 
It is worth mentioning that in the case of the non-symmetrical aryl/hetaryl thioketones $\mathbf{1 c}, \mathbf{1 f}-\mathbf{h}$ and 2-diazopropane (7a), the formed 1,3-dithiolanes $\mathbf{1 0}$ were isolated as mixtures of cis- and trans-isomers. In the ${ }^{1} \mathrm{H}$ NMR spectra, they could be identified based on the presence of two and one signal, respectively, for the $\mathrm{Me}_{2} \mathrm{C}(2)$ group. The mixtures of 1,3-dithiolanes $\mathbf{1 0}$ obtained from the reactions of diazoethane $(\mathbf{7 b})$ with thioketones $\mathbf{1 c}, \mathbf{f}$ consisted of only two instead of the expected three diastereoisomers. In all cases they belong to the same group of regioisomers. The regioselective formation of products $\mathbf{1 0}$ was proved by ${ }^{13} \mathrm{C}$ NMR spectroscopy: the signals attributed to $\mathrm{C}(2)$ were found in narrow regions at 54.9-59.4 ppm for 10c, $\mathbf{1 0 f}-\mathbf{h}$ and $43.1-45.6 \mathrm{ppm}$ for $\mathbf{1 0 m}, \mathbf{n}$, respectively. In addition, the structure of the sterically crowded 4,4,5,5-tetrasubstituted aryl/ hetaryl 1,3-dithiolanes $\mathbf{1 0}$ could be confirmed by the presence of only two signals for the three $\mathrm{C}\left(\mathrm{sp}^{3}\right)$-atoms of the heterocycle, whereas in the isomeric 2,2,4,4-tetraaryl/hetaryl 1,3dithiolanes, three signals for these atoms are expected (cf. [19]).

Trimethylsilyldiazomethane (7c) is widely applied as a practical and useful synthetic equivalent of the hazardous diazomethane $[24,25]$. In our earlier publications, its reactions with thiofluorenone (1b) and $S$-methyl (phosphonyl)dithioformate, leading to the expected 1,3,4-thiadiazoline derivatives, which are stable at $-60{ }^{\circ} \mathrm{C}$, were reported [26,27]. At higher temperature, in both reactions, dimers of the intermediate thiocarbonyl $S$-(trimethylsilyl)methanides were formed in the absence of a dipolarophile after evolution of $\mathrm{N}_{2}$. An analogous test experiment with 7c and thiobenzophenone (1a) was carried out in the course of the present study at $-75^{\circ} \mathrm{C}$, and in this case slow decolorization of the reaction solution was observed. In contrast to the experiment with $\mathbf{1 b}$, complete decolorization of the blue reaction solution was observed before the addition of the total, equimolar amount of 7c. After warming up and typical work-up procedure, the corresponding 1,3-dithiolane $\mathbf{1 0 0}$ and 1,4dithiane $4 \mathbf{c}$ in a ratio of 2:1 were found as products identified in the ${ }^{1} \mathrm{H}$ NMR spectrum of the crude reaction mixture. Thus, in this reaction dimerization of the intermediate thiocarbonyl ylide and its reaction with another molecule of 1 a were competitive pathways. Finally, the reactions of $7 \mathbf{c}$ with symmetrically substituted dihetaryl thioketones $\mathbf{1 d}$ and $\mathbf{1 e}$ were performed at $-75^{\circ} \mathrm{C}$, and in both cases, the sterically crowded 4,4,5,5-tetrahetaryl-1,3-dithiolanes 10r and 10s, respectively, were obtained as sole products.

The obtained results can be explained by the assumption that in the case of hetaryl thioketones $\mathbf{1}$ stepwise mechanisms via diradical intermediates govern the formation of the isolated 1,3dithiolanes 10 (Scheme 3). Based on earlier studies, the stability of 1,3,4-thiadiazolines $\mathbf{2}$, which are considered as potential precursors of thiocarbonyl ylides $\mathbf{3}$, should be increased by the introduction of $\mathrm{Me}$ or $\mathrm{Me}_{3} \mathrm{Si}$ groups. Upon this assumption, all reactions performed at $-75{ }^{\circ} \mathrm{C}$ should lead to the corresponding cycloadducts 2 with complete conversion of the starting thioketones 1 . Only after warming up above $-45 / 40{ }^{\circ} \mathrm{C}$ compounds 2 are expected to decompose yielding the reactive thiocarbonyl ylide 3. Under these conditions, the latter intermediates can undergo either 1,3-dipolar electrocyclization to give thiiranes 8 or dimerization leading to 1,4 -dithianes $4[20,26]$. This reaction course resulting in the exclusive formation of thiiranes $\mathbf{8}$ was observed in the case of thiobenzophenone (1a) and thiofluorenone (1b) with 2-diazopropane (7a). However, the reaction of 1b with $7 \mathbf{a}$ carried out at $-15{ }^{\circ} \mathrm{C}$ yielded also a small amount of 1,3-dithiolane $\mathbf{1 0 b}$. This result can be interpreted by the partial decomposition of $\mathbf{2} \mathbf{b}$ in the presence of the non-converted thioketone $\mathbf{1 b}$. The replacement of aromatic thioketones $\mathbf{1} \mathbf{a}, \mathbf{b}$ by di(thiophen-2-yl) thioketone (1d) in the reaction with $\mathbf{7 a}$ resulted in the formation of comparable amounts of thiirane $\mathbf{8 d}$ and 1,3-dithiolane $\mathbf{1 0 d}$, whereas at $-75^{\circ} \mathrm{C} \mathbf{8 d}$ is again the major product. It is worth mentioning that the analogous experiment carried out at $-60^{\circ} \mathrm{C}$, i.e., below the expected decomposition temperature of 1,3,4-thiadiazoline $\mathbf{2 d}$, led to substantial increase of the amount of 10d. A similar tendency was observed in other studied cases with hetaryl thioketones and 7a. The replacement of the latter by diazoethane (7b), leading to the less stable 1,3,4thiadiazolines $\mathbf{2}$, resulted in a general increase of the corresponding 1,3-dithiolanes $\mathbf{1 0}$, which were formed in substantial amounts, even in experiments performed at $-75^{\circ} \mathrm{C}$. However, the most striking results were observed in reactions performed with dihetaryl thioketones $\mathbf{1 d}$ and $\mathbf{1 e}$ with trimethylsilyldiazomethane (7c). In both experiments, the only products formed were the corresponding, sterically crowded 4,4,5,5,-tetrahetarylsubstituted 1,3-dithiolanes 10r and 10s. These results clearly demonstrate that 7c, similarly to diazomethane [22], reacts smoothly with dihetaryl thioketones 1 with no formation of the expected 1,3,4-thiadiazolines $\mathbf{2}$ and after release of $\mathrm{N}_{2}$ even at low temperature, the intermediate diradicals of type $\mathbf{3}$ attack the parent thioketones 1 yielding 1,3-dithiolanes 10 via stabilized 1,5-diradicals 12. In both cases no tendency for the formation of dimers of the intermediate 'thiocarbonyl ylide' was observed (Scheme 4).

Based on these results, the reaction mechanism can be proposed as formulated in Scheme 4. It seems likely that the first step comprising the reaction of a hetaryl thioketone $\mathbf{1}$ with $\mathbf{7 a}$, $\mathbf{7 b}$, and $7 \mathbf{c}$ is not a concerted process, but the diradical or zwitterionic intermediate of type $\mathbf{1 1}$ is formed and, depending on the number and type of stabilizing substituents and the reaction temperature, they undergo two competitive reactions: elimination of $\mathrm{N}_{2}$ leading to thiocarbonyl ylide 3 or 1,5-ring closure to give 1,3,4-thiadiazoline 2 . When the rapid elimination of $\mathrm{N}_{2}$ occurs in the presence of the non-converted thioketone $\mathbf{1}$, the 


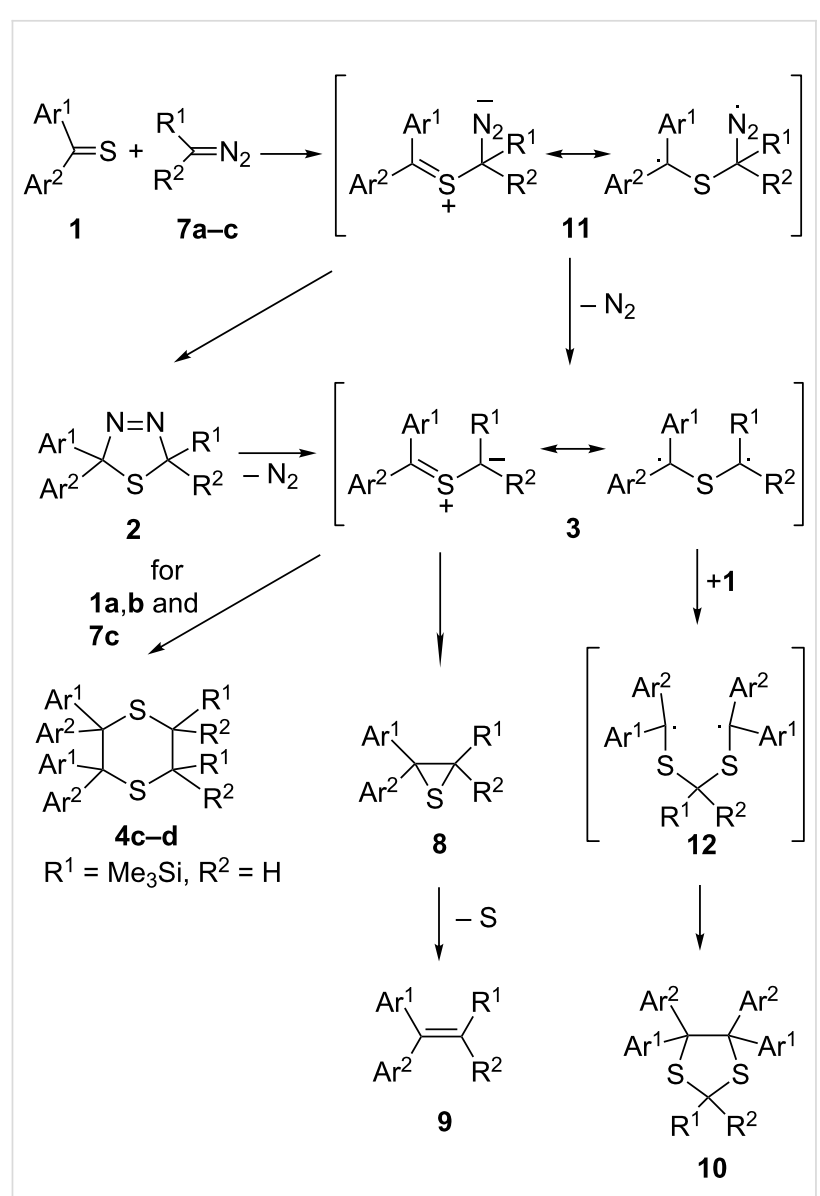

Scheme 4: Proposed competitive mechanisms in the reactions of aryl/ hetaryl and dihetaryl thioketones 1 with 2-diazopropane (7a), diazoethane (7b), and (trimethysilyl)diazomethane (7c).

stabilized 1,5-diradical $\mathbf{1 2}$ is formed as precursor of the sterically crowded 1,3-dithiolane $\mathbf{1 0}$. The alternatively formed 1,3,4thiadiazolines $\mathbf{2 a}$ and $\mathbf{2 b}$ are expected to be stable at $-75^{\circ} \mathrm{C}$ and eliminate $\mathrm{N}_{2}$ only at enhanced temperature generating thiocarbonyl ylide 3. As in that case the starting diaryl (or dihetaryl) thioketone $\mathbf{1}$ is completely consumed, the 1,3-dithiolane $\mathbf{1 0}$ cannot be formed. The results obtained with $7 \mathbf{c}$ demonstrate that its reaction with dihetaryl thioketones 1 occurs without formation of 1,3,4-thiadiazolines as intermediate [3+2]-cycloadducts. Elimination of $\mathrm{N}_{2}$ from the initially formed diradical of type 11 leads immediately to the new diradical species $\mathbf{3}$, which adds regioselectively to the $\mathrm{C}=\mathrm{S}$ group of the non-converted thioketone $\mathbf{1 .}$

This interpretation is consistent with the course of the reactions of aryl/hetaryl thioketones 1 with diazomethane, in which the formation of sterically crowded 1,3-dithiolanes side-by-side with 12-membered dimers of the thiocarbonyl ylide was observed [22]. In addition, it corresponds to the diradical mechanism postulated for the formal $[3+2]$-cycloaddition of aryl/ hetaryl thioketones 1 with the in situ generated thiocarbonyl $S$-methanides [28]. The missing formation of dimers from thiocarbonyl ylides 3 derived from hetaryl thioketones can be explained by steric hindrance resulting from the presence of the $\mathrm{Me}$ or $\mathrm{Me}_{3} \mathrm{Si}$ groups in the $S$-methanide moiety. However, electronic effects resulting from the diradical nature of the intermediate thiocarbonyl ylides, can also play certain role. The same effect was observed in the case of diaryldiazomethanes used in reactions with aryl/hetaryl thioketones $[29,30]$.

\section{Experimental}

General information: Melting points were determined in capillaries using a MEL-TEMP II apparatus (Aldrich) and are uncorrected. IR spectra were recorded with a FTIR NEXUS spectrophotometer as $\mathrm{KBr}$ pellets or as film; absorptions ( $v)$ in $\mathrm{cm}^{-1}$. ${ }^{1} \mathrm{H}$ and ${ }^{13} \mathrm{C}$ NMR spectra were measured on a Bruker Avance III $\left({ }^{1} \mathrm{H}\right.$ at 600 and ${ }^{13} \mathrm{C}$ at $\left.150 \mathrm{MHz}\right)$ instrument in $\mathrm{CDCl}_{3}$; chemical shifts $(\delta)$ are given in ppm, solvent signals as reference, coupling constants $(J)$ in $\mathrm{Hz}$. The multiplicity of the ${ }^{13} \mathrm{C}$ signals was deduced from DEPT, supported by ${ }^{1} \mathrm{H},{ }^{13} \mathrm{C}$ HMQC spectra. ${ }^{1} \mathrm{H}$ NMR data are presented as follows: chemical shift, multiplicity $(\mathrm{br}=$ broad, $\mathrm{s}=$ singlet, $\mathrm{d}=$ doublet, $\mathrm{t}=$ triplet, $\mathrm{q}=$ quartet, $\mathrm{m}=$ multiplet), coupling constant, integration. The mass spectra were recorded on a Finnigan MAT-95 (ESI). Elemental analyses were performed in the Microanalytical Laboratory of the Chemistry Faculty of the University of Łódź. Applied reagents such as 2-diazopropane (7a) and diazoethane (7b) were prepared by known methods according to the literature protocols [31,32]. Thiobenzophenone (1a), fluorene-9thione (thiofluorenone, 1b), symmetrical dihetaryl thioketones $\mathbf{1 d}, \mathbf{e}$, and nonsymmetrical aryl/hetaryl thioketones $\mathbf{1 c}, \mathbf{1 f}-\mathbf{h}$ were obtained from the corresponding ketones using the known procedures [33]. Other reagents used in the present study were commercially available.

Reaction of thioketones 1a-h with 2-diazopropane (7a) and diazoethane (7b) - General procedure: Corresponding thioketones $\mathbf{1 a}-\mathbf{h}(1 \mathrm{mmol})$ were dissolved in freshly distilled THF $(2.5 \mathrm{~mL})$ and the solution was cooled to the corresponding temperature $\left(-15,-60,-75^{\circ} \mathrm{C}\right.$; acetone/dry ice). Then, the mixture was treated with small portions of ethereal 2-diazopropane (7a) or diazoethane (7b) solution, until the intense color of the thioketone vanished. Then, the mixture was allowed to warm slowly to rt (ca. 2-4 h). After removal of the solvent under vacuum, the residue was subjected to ${ }^{1} \mathrm{H}$ NMR analysis in $\mathrm{CDCl}_{3}$ solution with a weighed amount of 1,1,2,2-tetrachloroethane as a standard. Crude products were purified by $\mathrm{CC}$ $\left(\mathrm{CHCl}_{3} /\right.$ hexane 2:8).

In crude mixtures obtained from 2-diazopropane (7a) and thioketones 1c,e,g,h and from diazoethane (7b) and thioketones 
1b-f, the presence of thiirane and the corresponding ethylene was evidenced based on the ${ }^{1} \mathrm{H}$ NMR spectra. In these cases, no isolation of the thiirane was performed; after addition of tris(dimethylamino)phosphine desulfurization leading to the ethane derivative was carried out.

Reaction of thioketones 1d-e with (trimethylsilyl)diazomethane (7c) - General procedure: The corresponding thioketones $1 \mathbf{d}-\mathbf{e}(1 \mathrm{mmol})$ were dissolved in freshly distilled THF $(2.5 \mathrm{~mL})$ and the solution was cooled to $-75{ }^{\circ} \mathrm{C}$ (acetone/ dry ice). Then, the mixture was treated with small portions of an ethereal solution of $7 \mathbf{c}(1 \mathrm{mmol})$. The mixture was kept in a cold bath, and the intense color of the thioketone vanished after $15 \mathrm{~min}$. Subsequently, the mixture was allowed to slowly warm to rt (ca. 2-4 h). After removal of the solvent under vacuum, the residue was subjected to the ${ }^{1} \mathrm{H} \mathrm{NMR}$ analysis in $\mathrm{CDCl}_{3}$ solution with a weighed amount of 1,1,2,2-tetrachloroethane as an internal standard. Crude products were purified by $\mathrm{CC}$ $\left(\mathrm{CHCl}_{3} /\right.$ hexane $\left.2: 8\right)$.

2,2-Dimethyl-3,3-diphenylthiirane (8a): Yield: $182 \mathrm{mg}$ (76\%). White crystals; mp 66-67 ${ }^{\circ} \mathrm{C}$ (chromatographic purification); IR (KBr) v: $2987(\mathrm{w}), 2921(\mathrm{w}), 1596(\mathrm{w}), 1490(\mathrm{~m})$, 1443 (m), 773 (m), 747 (m), $705(\mathrm{~s}), 691(\mathrm{~m}) \mathrm{cm}^{-1} ;{ }^{1} \mathrm{H}$ NMR $\left(600 \mathrm{MHz}, \mathrm{CDCl}_{3}\right) \delta$ 7.60-7.58 (m, 4H, $\left.\mathrm{H}_{\text {arom}}\right), 7.31-7.29(\mathrm{~m}$, $\left.4 \mathrm{H}, \mathrm{H}_{\text {arom }}\right), 7.23-7.21$ (m, 2H, $\left.\mathrm{H}_{\text {arom }}\right), 1.62\left(\mathrm{~s}, 6 \mathrm{H}, \mathrm{CH}_{3}\right) \mathrm{ppm}$; ${ }^{13} \mathrm{C} \mathrm{NMR}\left(150 \mathrm{MHz}, \mathrm{CDCl}_{3}\right) \delta 142.4$ (for $2 \mathrm{C}_{\text {arom }}$ ), 129.4, 127.9, 126.8 (for $10 \mathrm{CH}_{\text {arom }}$ ), 67.8, 52.9 (C-2, C-3), 27.9 $\left(2 \mathrm{CH}_{3}\right)$ ppm; ESIMS m/z (\%): $241\left(100,[\mathrm{M}+\mathrm{H}]^{+}\right)$; anal. calcd for $\mathrm{C}_{16} \mathrm{H}_{16} \mathrm{~S}$ (240.36): C, 79.95; H, 6.71; S, 13.34; found: $\mathrm{C}$, 79.69; H, 6.50; S, 13.40 .

1,1-Di(thiophen-2-yl)-2-methylpropene (9d): Yield: $4 \mathrm{mg}$ (2\%). Yellow oil; IR (film) v: 2927 (w), 2908 (w), 2850 (w), 1436 (m), 1369 (m), 1227 (m), $1016(\mathrm{w}), 827$ (m), 693 (s) $\mathrm{cm}^{-1} ;{ }^{1} \mathrm{H}$ NMR $\left(600 \mathrm{MHz}, \mathrm{CDCl}_{3}\right) \delta 7.29(\mathrm{~d}, J=5.4 \mathrm{~Hz}, 2 \mathrm{H}$, $\mathrm{H}_{\text {arom }}$ ), 7.04-7.02 (m, 2H, $\left.\mathrm{H}_{\text {arom }}\right), 6.91$ (d, $J=3.6 \mathrm{~Hz}, 2 \mathrm{H}$, $\left.\mathrm{H}_{\text {arom }}\right), 2.03$ (s, 6H, $\left.\mathrm{CH}_{3}\right)$ ppm; ${ }^{13} \mathrm{C} \mathrm{NMR}\left(150 \mathrm{MHz}, \mathrm{CDCl}_{3}\right)$ $\delta 144.9,137.1\left(\mathrm{C}_{\text {arom }}, \mathrm{C}_{\text {arom }}-\mathrm{C}=\right.$ ), 126.6, 126.4, 124.9 (for 6 $\left.\mathrm{CH}_{\text {arom }}\right), 122.9\left(\mathrm{C}=\mathrm{C}\left(\mathrm{CH}_{3}\right)_{2}\right), 23.3\left(2 \mathrm{CH}_{3}\right) \mathrm{ppm}$; anal. calcd for $\mathrm{C}_{12} \mathrm{H}_{12} \mathrm{~S}_{2}$ (220.35): C, 65.41; H, 5.49; S, 29.10; found: C, 65.31; H, 5.76; S, 28.81.

2,2-Dimethyl-4,5-diphenyl-4,5-di(thiophen-2-yl)-1,3-dithiolane (10f): Isolated as a mixture of cis-, trans-isomers (crude product ratio 65:35). Yield: $142 \mathrm{mg}$ (63\%). White crystals; mp 153-154 ${ }^{\circ} \mathrm{C}\left(\mathrm{MeOH} / \mathrm{CHCl}_{3}\right)$; IR (KBr) v: 3062 (w), 2919 (w), 1595 (w), 1490 (m), 1443 (m), $1231(\mathrm{~m}), 1156(\mathrm{~m}), 854(\mathrm{w}), 697(\mathrm{~s}) \mathrm{cm}^{-1} ;{ }^{1} \mathrm{H}$ NMR $\left(600 \mathrm{MHz}, \mathrm{CDCl}_{3}\right) \delta 7.59-6.68\left(\mathrm{~m}, 32 \mathrm{H}, \mathrm{H}_{\text {arom }}\right), 1.86(\mathrm{~s}, 3 \mathrm{H}$, $\mathrm{CH}_{3}$-cis), 1.70 (s, 6H, $\mathrm{CH}_{3}$-trans), 1.39 (s, 3H, $\mathrm{CH}_{3}$-cis) ppm;
${ }^{13} \mathrm{C}$ NMR (150 MHz, $\mathrm{CDCl}_{3}$ ) $\delta 151.2,149.8,144.0,142.9$ (for $\left.8 \mathrm{C}_{\text {arom }}\right), 131.3,131.1,130.5,127.5,127.1,127.0,126.6,126.1$, 125.4, 125.2, 125.0 (for $32 \mathrm{CH}_{\text {arom }}$ ), 78.8, 78.4 (C-4 + C-5, for cis and trans), 55.4, 55.3 (C-2, cis and trans) $33.1\left(\mathrm{CH}_{3}-\right.$ cis $)$, 32.9 (for $2 \mathrm{CH}_{3}$-trans), $32.5\left(\mathrm{CH}_{3}\right.$-cis) ppm; anal. calcd for $\mathrm{C}_{25} \mathrm{H}_{22} \mathrm{~S}_{4}$ (450.70): C, 66.62; H, 4.92; S, 28.46; found: $\mathrm{C}$, 66.46; H, 4.91; S, 28.33 .

1,1-Di(thiophen-2-yl)-propene (9k): Yield: $52 \mathrm{mg}$ (25\%) After desulfurization of tiirane 8k. Yellow oil; IR (film) v: 3104 (w), $3071(\mathrm{w}), 2930(\mathrm{w}), 2908$ (w), $2850(\mathrm{w}), 1438(\mathrm{~m}), 1362$ (w), $1249(\mathrm{~m}), 1223(\mathrm{~m}), 1036(\mathrm{w}), 850(\mathrm{~s}), 836(\mathrm{~s}), 818(\mathrm{~s})$, $695(\mathrm{~s}) \mathrm{cm}^{-1} ;{ }^{1} \mathrm{H} \mathrm{NMR}\left(600 \mathrm{MHz}, \mathrm{CDCl}_{3}\right) \delta 7.23-7.22(\mathrm{~m}, 1 \mathrm{H}$, $\mathrm{H}_{\text {arom }}$ ), 7.01-7.00 (m, 1H, $\left.\mathrm{H}_{\text {arom }}\right), 6.96-6.94$ (m, 1H, $\left.\mathrm{H}_{\text {arom }}\right)$, 6.90-6.89 (m, 1H, $\left.\mathrm{H}_{\text {arom }}\right), 6.80-6.79\left(\mathrm{~m}, 1 \mathrm{H}, \mathrm{H}_{\text {arom }}\right), 6.71-6.70$ $\left(\mathrm{m}, 1 \mathrm{H}, \mathrm{H}_{\text {arom }}\right), 6.18(\mathrm{q}, J=7.2 \mathrm{~Hz}, 1 \mathrm{H},=\mathrm{CH}), 1.74(\mathrm{~d}, J=7.2$ $\left.\mathrm{Hz}, 3 \mathrm{H}, \mathrm{CH}_{3}\right) \mathrm{ppm} ;{ }^{13} \mathrm{C} \mathrm{NMR}\left(150 \mathrm{MHz}, \mathrm{CDCl}_{3}\right) \delta 129.4$, $139.8,146.8\left(2 \mathrm{C}_{\text {arom }}, \mathrm{C}_{\text {arom }}, C=\right), 127.6,127.0,126.6,126.3$, 125.5, 124.8, $123.4\left(6 \mathrm{CH}_{\text {arom, }}=\mathrm{CH}\right), 15.6\left(\mathrm{CH}_{3}\right) \mathrm{ppm}$; anal. calcd for $\mathrm{C}_{11} \mathrm{H}_{10} \mathrm{~S}_{2}$ (206.33): C, 64.04; H, 4.89; S, 31.08; found: $\mathrm{C}, 63.83 ; \mathrm{H}, 4.98 ; \mathrm{S}, 31.14$.

2-Trimethylsilyl-4,4,5,5-tetra(thiophen-2-yl)-1,3-dithiolane (10r): Yield: $220 \mathrm{mg}$ (87\%). Yellow crystals: $\mathrm{mp} 152-154{ }^{\circ} \mathrm{C}$ (hexane/ $\mathrm{CH}_{2} \mathrm{Cl}_{2}$ ); IR (KBr) v: $2951(\mathrm{w}), 1618(\mathrm{w}), 1424(\mathrm{~m})$, $1250(\mathrm{~s}), 1232(\mathrm{~m}), 1122(\mathrm{~m}), 1077$ (m), 1050 (m), 842 (s), 752 (s), 699 (s), $632(\mathrm{~m}) \mathrm{cm}^{-1} ;{ }^{1} \mathrm{H} \mathrm{NMR}\left(600 \mathrm{MHz}, \mathrm{CDCl}_{3}\right) \delta$ 7.23-7.22 (m, 2H, $\left.\mathrm{H}_{\text {arom }}\right), 7.20-7.19$ ( $\left.\mathrm{m}, 2 \mathrm{H}, \mathrm{H}_{\text {arom }}\right), 6.96-6.95$ (m, 2H, $\left.\mathrm{H}_{\text {arom }}\right), 6.89-6.87\left(\mathrm{~m}, 2 \mathrm{H}, \mathrm{H}_{\text {arom }}\right), 6.83-6.81(\mathrm{~m}, 4 \mathrm{H}$, $\left.\mathrm{H}_{\text {arom }}\right), 3.89\left(\mathrm{~s}, 1 \mathrm{H},\left(\left(\mathrm{CH}_{3}\right)_{3} \mathrm{Si}\right) H \mathrm{C}\right), 0.34\left(\mathrm{~s}, 9 \mathrm{H},\left(\mathrm{CH}_{3}\right)_{3} \mathrm{Si}\right)$ ppm; $\left.{ }^{13} \mathrm{C} \mathrm{NMR} \mathrm{(150} \mathrm{MHz,} \mathrm{CDCl}_{3}\right) \delta 148.1,146.1$ (for 4 $\mathrm{C}_{\text {arom) }}, 130.2,129.4,127.0,125.6,125.5,125.4$ (for 12 $\left.\mathrm{CH}_{\text {arom }}\right), 74.9$ (C-4, C-5), 36.5 (C-2), -1.53 (( $\left.\left.\mathrm{CH}_{3}\right)_{3} \mathrm{Si}\right) \mathrm{ppm}$; anal. cald for $\mathrm{C}_{22} \mathrm{H}_{22} \mathrm{~S}_{6} \mathrm{Si}$ (506.89): C, 52.13; H, 4.37; S, 37.96; found: C, 52.44; H, 4.55; S,37.71.

\section{Supporting Information}

\section{Supporting Information File 1}

Experimental data for selected compounds 8-10, and the original ${ }^{1} \mathrm{H}$ and ${ }^{13} \mathrm{C}$ NMR spectra for all products.

[http://www.beilstein-journals.org/bjoc/content/ supplementary/1860-5397-12-71-S1.pdf]

\section{Acknowledgements}

The authors thank the National Science Center (Cracow, Poland) for generous financial support (Grant Maestro-3 (Dec2012/06/A/ST5/00219). Skilful performance of microanalyses by Ms Hanna Jatczak and Ms Agnieszka Cieślińska (University of Łódź) is gratefully acknowledged. 


\section{References}

1. Padwa, A., Ed. 1,3-Dipolar Cycloaddition Chemistry; John Wiley \& Sons: Hoboken, NJ, U.S.A., 1984; Vol. 1, 2.

2. Padwa, A.; Pearson, W. H., Eds. Synthetic Applications of 1,3-Dipolar Cycloaddition Chemistry Toward Heterocycles and Natural Products; John Wiley \& Sons: Hoboken, NJ, U.S.A., 2002.

3. Sustmann, R. Pure Appl. Chem. 1974, 40, 569-593. doi:10.1351/pac197440040569

4. Huisgen, R. Angew. Chem., Int. Ed. 1963, 2, 565-598. doi:10.1002/anie.196305651

5. Huisgen, R. J. Org. Chem. 1976, 41, 403-419. doi:10.1021/jo00865a001

6. Woodward, R. B.; Hoffmann, R. Angew. Chem., Int. Ed. Engl. 1969, 8, 781-853. doi:10.1002/anie.196907811

7. Fukui, K.; Yonezawa, T.; Shingu, H. J. Chem. Phys. 1952, 20, 722-725. doi:10.1063/1.1700523

8. Huisgen, R.; Mloston, G.; Giera, H.; Langhals, E. Tetrahedron 2002, 58, 507-519. doi:10.1016/S0040-4020(01)01147-4

9. Huisgen, R.; Mloston, G.; Langhals, E. Helv. Chim. Acta 2001, 84, 1805-1820. doi:10.1002/1522-2675(20010613)84:6<1805::AID-HLCA1805>3.0.CO ;2-T

10. Khlebnikov, A. F.; Konev, A. S.; Virtsev, A. A.; Yufit, D. S.; Mloston, G.; Heimgartner, H. Helv. Chim. Acta 2014, 97, 453-470. doi:10.1002/hlca.201300405

11. Jasiński, R. J. Fluorine Chem. 2015, 176, 35-39. doi:10.1016/j.jluchem.2015.04.020

12. Siadati, S. A. Tetrahedron Lett. 2015, 56, 4857-4863. doi:10.1016/j.tetlet.2015.06.048

13. Firestone, R. A. J. Org. Chem. 1968, 33, 2285-2290. doi:10.1021/jo01270a023

14. Firestone, R. A. Tetrahedron 1977, 33, 3009-3039. doi:10.1016/0040-4020(77)80448-1

15. Firestone, R. A. Int. J. Chem. Kinet. 2013, 45, 415-428. doi:10.1002/kin.20776

16. Kalwinsch, I.; Li, X.; Gottstein, J.; Huisgen, R. J. Am. Chem. Soc. 1981, 103, 7032-7033. doi:10.1021/ja00413a073

17. Huisgen, R.; Mloston, G.; Giera, H.; Langhals, E.; Polborn, K.; Sustmann, R. Eur. J. Org. Chem. 2005, 1519-1531. doi:10.1002/ejoc.200400765

18. Huisgen, R.; Li, X.; Mloston, G.; Knorr, R.; Stephenson, D. S. Tetrahedron 1999, 55, 12783-12796 doi:10.1016/S0040-4020(99)00790-5

19. Huisgen, R.; Li, X.; Mlostoń, G.; Fluka, C. Eur. J. Org. Chem. 2000, 1695-1702. doi:10.1002/(SICI)1099-0690(200005)2000:9<1695::AID-EJOC1695>3 .0.CO;2-4

20. Huisgen, R.; Kalwinsch, I.; Li, X.; Mloston, G. Eur. J. Org. Chem. 2000, 1685-1694. doi:10.1002/(SICI)1099-0690(200005)2000:9<1685::AID-EJOC1685>3 .0.CO;2-6

21. Oae, S. Organic Sulfur Chemistry: Structure and Mechanism; CRC Press, Inc.: Boca Raton, FL, U.S.A., 1992.

22. Mlostoń, G.; Urbaniak, K.; Linden, A.; Heimgartner, H. Helv. Chim. Acta 2015, 98, 453-461. doi:10.1002/hlca.201500050

23. Schönberg, A.; Cernik, D.; Urban, W. Ber. Dtsch. Chem. Ges. 1931, 64, 2577-2581. doi:10.1002/cber.19310640941

24. Shioiri, T.; Aoyama, T.; Snowden, T. e-EROS Encyclopedia of Reagents for Organic Synthesis, 2006. doi:10.1002/047084289X.rt298.pub2
25. Fuchs, L. P., Ed. Handbook of Reagents for Organic Synthesis, Reagents for Silicon-Mediated Organic Synthesis; John Wiley \& Sons: Hoboken, NJ, U.S.A., 2011; p 590.

26. Mlostoń, G.; Urbaniak, K.; Linden, A.; Heimgartner, H. Pol. J. Chem. 2007, 81, 1849-1860.

27. Mloston, G.; Urbaniak, K.; Linden, A.; Heimgartner, B. Heterocycles 2007, 73, 419-432. doi:10.3987/COM-07-S(U)12

28. Mlostoń, G.; Pipiak, P.; Linden, A.; Heimgartner, H. Helv. Chim. Acta 2015, 98, 462-473. doi:10.1002/hlca.201500057

29. Mlostoń, G.; Urbaniak, K.; Pawlak, A.; Heimgartner, H. Heterocycles 2016, in press. doi:10.3987/COM-15-S(T)8

30. Mlostoń, G.; Hamera, R.; Heimgartner, H. Phosphorus, Sulfur Silicon Relat. Elem. 2015, 190, 2125-2133. doi:10.1080/10426507.2015.1071817

31. Schweizer, E. E.; Kim, C. S. J. Org. Chem. 1971, 36, 4033-4041. doi:10.1021/jo00825a006

32. Hudlicky, T.; Short, R. P. J. Org. Chem. 1982, 47, 1522-1527. doi:10.1021/jo00347a031

33. Mlostoń, G.; Urbaniak, K.; Gębicki, K.; Grzelak, P.; Heimgartner, H. Heteroat. Chem. 2014, 25, 548-555. doi:10.1002/hc.21191

\section{License and Terms}

This is an Open Access article under the terms of the Creative Commons Attribution License (http://creativecommons.org/licenses/by/2.0), which permits unrestricted use, distribution, and reproduction in any medium, provided the original work is properly cited.

The license is subject to the Beilstein Journal of Organic Chemistry terms and conditions:

(http://www.beilstein-journals.org/bjoc)

The definitive version of this article is the electronic one which can be found at: doi:10.3762/bjoc. 12.71 